IZA DP No. 6287

Chinese Immigrants in the U.S. Labor Market: Effects of Post-Tiananmen Immigration Policy

Pia Orrenius

Madeline Zavodny

Emily Kerr

January 2012 


\title{
Chinese Immigrants in the U.S. Labor Market: Effects of Post-Tiananmen Immigration Policy
}

\author{
Pia Orrenius \\ Federal Reserve Bank of Dallas \\ and IZA \\ Madeline Zavodny \\ Agnes Scott College \\ and IZA \\ Emily Kerr \\ Federal Reserve Bank of Dallas
}

Discussion Paper No. 6287

January 2012

IZA

P.O. Box 7240

53072 Bonn

Germany

Phone: +49-228-3894-0

Fax: +49-228-3894-180

E-mail: iza@iza.org

Any opinions expressed here are those of the author(s) and not those of IZA. Research published in this series may include views on policy, but the institute itself takes no institutional policy positions.

The Institute for the Study of Labor (IZA) in Bonn is a local and virtual international research center and a place of communication between science, politics and business. IZA is an independent nonprofit organization supported by Deutsche Post Foundation. The center is associated with the University of Bonn and offers a stimulating research environment through its international network, workshops and conferences, data service, project support, research visits and doctoral program. IZA engages in (i) original and internationally competitive research in all fields of labor economics, (ii) development of policy concepts, and (iii) dissemination of research results and concepts to the interested public.

IZA Discussion Papers often represent preliminary work and are circulated to encourage discussion. Citation of such a paper should account for its provisional character. A revised version may be available directly from the author. 


\section{ABSTRACT \\ Chinese Immigrants in the U.S. Labor Market: Effects of Post-Tiananmen Immigration Policy*}

The Tiananmen Square protests in 1989 and ensuing government crackdown affected Chinese nationals not only at home but around the world. The U.S. government responded to the events in China by enacting multiple measures to protect Chinese nationals present in the U.S. It first suspended all forced departures among Chinese nationals present in the country as of June 1989 and later gave them authorization to work legally. The Chinese Student Protection Act, passed in October 1992, made those Chinese nationals eligible for lawful permanent resident status. These actions applied to about 80,000 Chinese nationals residing in the U.S. on student or other temporary visas or illegally. Receiving permission to work legally and then a green card is likely to have affected recipients' labor market outcomes. This study uses 1990 and 2000 census data to examine employment and earnings among Chinese immigrants who were likely beneficiaries of the U.S. government's actions. Relative to immigrants from Hong Kong, Taiwan, and South Korea - countries not covered by the post-Tiananmen immigration policy measures - highly-educated immigrants from mainland China experienced significant employment and earnings gains during the 1990s. Chinese immigrants who arrived in the U.S in time to benefit from the measures also had higher relative earnings in 2000 than Chinese immigrants who arrived too late to benefit. The results suggest that getting legal work status and then a green card has a significant positive effect on skilled migrants' labor market outcomes.

JEL Classification: J15

Keywords: immigration, Chinese Student Protection Act, employment, earnings

Corresponding author:

Pia Orrenius

Federal Reserve Bank of Dallas

2200 N. Pearl Street

Dallas, TX 75201

USA

E-mail: Pia.Orrenius@dal.frb.org

\footnotetext{
* Jingsi Zu provided excellent research assistance. We thank Fanying Kong for helpful conversations, as well as Marie Mora, Christina Gathmann, and participants at the 2010 TEMPO conference on international migration, the 2010 Southern Economic Association conference, and the 2011 Allied Social Science Associations meeting for helpful suggestions. The opinions expressed herein are those of the authors and do not necessarily reflect the views of the Federal Reserve Bank of Dallas or the Federal Reserve System.
} 


\section{Chinese Immigrants in the U.S. Labor Market: Effects of Post-Tiananmen Immigration Policy}

\section{INTRODUCTION}

The United States has a long history of singling out Chinese immigrants for special treatment, good and bad. ${ }^{1}$ After the 1882 Chinese Exclusion Act, most Chinese immigrants were barred from entering the country for over a half-century. More than one hundred years later, the U.S. granted special privileges to Chinese immigrants in response to the Tiananmen Square protests that culminated in violence and deaths in June 1989. Soon after the dramatic events in Beijing, the Bush administration declared that Chinese nationals would not be involuntarily returned to China. This deferred enforced departure program was intended to protect students who were involved in the protests from abroad from possible reprisal if they had to return to China. It also signaled Washington's displeasure with the events in Beijing.

The U.S. later granted additional privileges to Chinese nationals residing in the U.S. An executive order issued in April 1990 deferred deportations and granted employment authorization to Chinese nationals who were in the U.S. at the time of, or soon after, the dramatic events in Tiananmen. The Chinese Student Protection Act (CSPA), signed into law in October 1992, allowed Chinese nationals who were present in the U.S. at the time of the executive order to apply for legal permanent resident status (LPR, or "green cards"). About 80,000 Chinese nationals applied for and were granted deferred enforced departure, and 70,000 later received authorization to stay and work under the executive order (Brooks, 1992). Over 53,000 people ultimately received green cards under the CSPA.

This paper examines how these unprecedented actions appear to have affected Chinese immigrants' employment and earnings relative to other groups of Asian immigrants. The

\footnotetext{
${ }^{1}$ This paper uses the term "immigrant" to refer to individuals born abroad to non-U.S. citizen parents.
} 
measures allowed Chinese immigrants to bypass the need to find an employer to sponsor them for a temporary work visa or a green card, and gave them easier access to green cards than they otherwise would have had. The results therefore give insight into how getting permanent resident status affects skilled migrants.

\section{BACKGROUND}

The U.S. government's unprecedented protective measures covered all Chinese nationals, not just students. In 1990, the non-naturalized Chinese population present in the U.S. numbered almost 300,000 (U.S. Bureau of the Census, 1993). In addition to legal permanent residents, this population included about 40,000 to 43,000 Chinese students and scholars (Brooks, 1992; Mann, 1990) and about 70,000 unauthorized immigrants (INS, 2003). Students accounted for about onehalf of applicants for the deferred enforced departure program (Brooks, 1992). Some observers speculated that unauthorized immigrants from China were a major beneficiary of the protective measures (Myers, 1994; Poston and Luo, 2006).

Students, unauthorized immigrants, and other immigrants from mainland China (the People's Republic of China, or PRC) all benefitted from the executive order and then the CSPA. The executive order allowed any Chinese national residing in the U.S in the aftermath of the Tiananmen Square protests to stay and work legally for several years regardless of their visa type and legal status at the time of the order. The CSPA then removed any hurdles to permanent residence. Absent the CSPA, students eligible to stay in the U.S. would have had to find an employer or relative willing to sponsor them for a non-immigrant visa or green card, while unauthorized immigrants had no clear route to legal status. The executive order and the CSPA 
thus gave Chinese nationals more labor market flexibility and a clear pathway to permanent residence, removing uncertainty and worries about their immigration status.

These measures are likely to have affected beneficiaries' labor market outcomes. The executive order and the CSPA should have increased the likelihood of employment among some beneficiaries but could have lowered it among others. Among skilled migrants, the measures are likely to have increased employment by relaxing constraints on where they could work. Students and scholars who were limited to on-campus jobs by the terms of their visas became able to work in any sector. Accompanying dependents who were barred from employment entirely by the terms of their visas became eligible to work. On the other hand, the measures made covered Chinese nationals eligible for public assistance programs. This may have reduced beneficiaries' labor supply, particularly among low-skilled migrants. And, of course, concomitant changes in earnings may have affected labor supply within households.

The U.S. immigration policy changes should have boosted beneficiaries' earnings, even among those already working. Beneficiaries who were working under the table became able to work legally, enabling them to move to higher-paying jobs. Earnings likely increased for students and their spouses since the former now had more options about where to work while the latter now were allowed to work. Government-financed students and scholars who held exchange visitor (J-1) visas that required them to return to China within 18 months of completing their studies no longer had to do so, making them more attractive to employers. Temporary work visa holders were no longer tied to the employer specified by their work visa, making it easier for them to move to higher-paying positions. Beneficiaries no longer had to search for an employer willing to sponsor them for a temporary work visa or a green card, giving them more latitude in their job searches. 
Little is known about the magnitude of the effects of the executive order and the CSPA on Chinese nationals' labor market outcomes. We are aware of only one study that has examined labor market outcomes among CSPA beneficiaries. Lan (2009) shows that, by raising the probability of having a green card, the CSPA lowered the likelihood that Chinese $\mathrm{PhD}$ recipients held a post-doctoral position relative to Indian $\mathrm{PhD}$ recipients. Because they were not subject to limits on skilled temporary (H-1B) visas or on permanent visas, CSPA beneficiaries presumably were better able to move into non-academic or permanent positions than similarly-educated Indian immigrants. Our study essentially addresses the same question—namely, what is the payoff to being able to transition directly to a green card from a student or other temporary visa—but among a broader sample of Chinese immigrants.

Immigrants working on temporary visas appear to experience substantial earnings gains upon receiving permanent resident status. One study finds the annual wage gain associated with an employment-based green card was almost $\$ 12,000$ in the New Immigrant Survey (Mukhopadhyay and Oxborrow, 2010). Another study suggests that getting an employmentbased green card raised workers' wages by 18 to 25 percent (Gass Kandilov, 2007). Both studies attribute the wage gains to enhanced job mobility.

These green-card wage gains do not appear to be limited to the skilled workers who tend to get employment-based green cards. Mexicans who marry U.S. natives - the fastest route to a green card - earn 30 percent more than other Mexicans relative to the similar difference among Puerto Ricans, who are U.S. citizens by birth, suggesting there is a substantial earnings premium from having a green card (Chi and Drewianka, 2010).

More broadly, research shows that legalization programs that grant permanent residence to previously unauthorized immigrants improve beneficiaries' labor market outcomes, 
particularly their earnings. Estimates suggest that Latin American immigrants who legalized their status under the 1986 Immigration Reform and Control Act (IRCA) experienced wage increases in the range of 6 to 13 percent, with slightly larger effects among women than among men (Kossoudji and Cobb-Clark, 2002; Rivera-Batiz, 1999). One study concludes that employment rates fell among immigrants who legalized their status under IRCA; men became more selective about the jobs they were willing to hold while women exited the labor force, perhaps because they became eligible for more government transfer programs after they became legal (AmuedoDorantes, Bansak, and Raphael, 2007). Another study, however, concludes that employment rates rose among female immigrants who likely benefitted from IRCA (Pan, 2010). The 1997 Nicaraguan Adjustment and Central American Relief Act (NACARA) appears to have reduced, albeit insignificantly, male beneficiaries' employment. Similar to the IRCA experience, earnings increased for men who legalized their status under NACARA (Kaushal, 2006).

The immigrants who benefitted from the U.S. immigration policy response to the Tiananmen Square tragedy were different in several ways from those who benefitted from earlier legalization programs in the U.S. The deferred enforced departure program, the executive order, and the CSPA were, of course, limited to certain immigrants from mainland China. Immigrants who legalized their status under IRCA were predominately from Latin America, while NACARA eligibility was almost exclusively limited to certain immigrants from Nicaragua, Cuba, El Salvador, and Guatemala. As noted above, about one-half of CSPA beneficiaries were on student visas, most of whom were graduate students $(\mathrm{Fu}, 1995)$. The vast majority of IRCA recipients, in contrast, had entered the U.S. illegally (Rytina, 2002), and the same is likely true of NACARA beneficiaries given their countries of origin. 
CSPA beneficiaries presumably were more skilled, on average, than the typical green card recipient and much more skilled than the beneficiaries of previous legalization programs. Kaushal (2006) and Pan (2010) conclude that the positive wage effects of NACARA and IRCA, respectively, were much larger among men with at least a high school diploma than among the less educated. Relatively skilled immigrants were better able to move into higher-paying occupations when they legalized their status. Consistent with this, Gass Kandilov (2007) and Mukhopadhyay and Oxborrow (2010) report wage effects among workers transitioning from non-immigrant work visas to green cards — who tend to be more skilled —at the upper end of those reported by the legalization literature. The executive order and the CSPA therefore likely had a sizable effect on beneficiaries' earnings.

The measures also may have had a large positive effect on beneficiaries' employment since many recipients were students or scholars supported by their home government or universities, not unauthorized immigrants who had to work in order to survive or people present in the U.S. on non-immigrant work visas. Before the executive order, students and scholars were very limited in what jobs they were allowed to hold, and their accompanying spouses were not allowed to work at all. Many may have increased their labor supply when those limitations were removed. Employment effects are likely to have been larger among women than men since a greater proportion of women held visas that did not allow them to work at all before the executive order.

In the analysis below, we use data from the 1990 and 2000 censuses to examine how labor market outcomes among immigrants from mainland China may have been affected by the U.S. immigration policy response to Tiananmen. We compare PRC immigrants to their counterparts from Hong Kong, Taiwan, and Korea, who were not directly affected by the CSPA 
and related measures. We focus on immigrants who have at least a bachelor's degree and are aged 25-39 in 1990.

\section{CHARACTERISTICS OF CSPA RECIPIENTS}

In order to assess the effects of the U.S. immigration policy response to Tiananmen, we first need to understand who benefitted from the policies. Although the U.S. government's actions were important to some mainland Chinese immigrants, not all Chinese immigrants were eligible and some did not need the policies' protections. Executive order no. 12711 was issued on April 11, 1990, and applied to Chinese nationals who were in the U.S. on or after June 5, 1989 — the day after shootings commenced at Tiananmen Square - up to the day the order was issued. The CSPA was signed into law on October 9, 1992, and applied to Chinese nationals who arrived in the U.S. on or before the day of the executive order and remained in the U.S. essentially continuously until the day the act was signed. The measures thus protected only Chinese immigrants who were in the U.S. by a particular date. Chinese immigrants who already had a green card or had become naturalized citizens did not need the measures' protections.

The CSPA was an important avenue for Chinese nationals to receive LPR status. Figure 1 shows the number of LPR recipients from mainland China during fiscal years (FY) 1980-2000 and the number of those admitted under the CSPA. CSPA beneficiaries comprised two-fifths of LPR recipients from mainland China during FY 1993 and 1994. ${ }^{2}$ The number of mainland Chinese immigrants granted LPR status spiked in those two years. The spike was largely the result of the CSPA but also reflected two other changes. First, the Immigration Act of 1990

\footnotetext{
${ }^{2}$ The application period for green cards under the CSPA was the 12 month period beginning July 1, 1993. Over 90 percent of green cards granted under the CSPA were awarded in FY 1993 or 1994. INS data indicate that a very small fraction ( 0.3 percent) of CSPA beneficiaries was born in a country other than the People's Republic of China (mainland China).
} 
began affecting admissions in FY 1992. That act increased the number of visas available in employment-based categories, making it easier for skilled immigrants from China and elsewhere to receive LPR status. Second, the CSPA included a provision that reduced the number of visas issued to mainland Chinese immigrants by 1,000 per year in later years to offset the visas issued under the CSPA.

Table 1 shows characteristics of LPR recipients under the CSPA during FY 1993-95, the period when 99 percent of CSPA beneficiaries received green cards. For comparison, it also shows characteristics of other LPR recipients from mainland China (PRC) during 1982-90, the period when the vast majority of CSPA beneficiaries entered the U.S. ${ }^{3}$ The table reports characteristics of LPR recipients from Hong Kong, Taiwan, and Korea during 1982-90 as well since those immigrants are part of the comparison groups in the regression analysis below. ${ }^{4}$ The table is based on INS public use microdata on all LPR recipients at the time they applied for green cards.

Immigrants who received LPR status under the CSPA differ from other LPR recipients from mainland China and the other countries in several ways. As Table 1 shows, CSPA beneficiaries are younger, on average, than other LPR recipients from mainland China but older than those from Hong Kong, Taiwan, and Korea. Considerably more CSPA beneficiaries are male. The occupational distributions differ as well.

All of the CSPA beneficiaries were already in the U.S. when they applied for and received a green card, meaning that they adjusted from nonimmigrant (temporary) status. For the

\footnotetext{
${ }^{3}$ We would prefer to report the characteristics of LPR recipients during 1980-90 to match the census data we use below. However, the INS data combine Taiwan and mainland China until 1982. For comparability, we begin the Hong Kong and Korea series in the INS data in 1982 as well.

${ }^{4}$ Hong Kong was a British territory until 1997, when it became a special administrative region of the PRC. For simplicity and because our sample is comprised of individuals who migrated to the U.S. by 1990, we refer here to Hong Kong as a country. The INS data do not distinguish between North and South Korea, but almost all immigrants are likely to be from South Korea given the difficulty of leaving North Korea.
} 
other groups, the majority of LPR recipients entered the U.S. with a green card rather than adjusted from nonimmigrant status while already present in the country. Compared to LPR recipients in the other groups who did adjust their status, CSPA beneficiaries were more likely to have last been admitted to the U.S. on a student visa.

All told, over 75 percent of CSPA beneficiaries were last admitted to the U.S. on some type of skilled visa, including student, exchange visitor, and skilled worker visas, and visas for accompanying dependents in those categories. Interestingly, less than 1 percent of CSPA beneficiaries reported entering without inspection on their last entry to the U.S. and only 6 percent did not report how they last entered the country (not shown). This suggests that claims that unauthorized immigrants were major beneficiaries of the CSPA may have been overstated, although we do not know how many CSPA beneficiaries had overstayed their visas.

The LPR recipients characterized in Table 1 are a subset of the foreign born who are in the decennial census data we use in the analysis below. Other foreign born who are in the census data include people who received their green card longer ago, people who had become naturalized U.S. citizens, students and other non-immigrant visa holders who were living temporarily in the U.S., and unauthorized immigrants; temporary visitors for business or pleasure are unlikely to appear in the census. We now turn to an explanation of how we use the census data to examine how labor force outcomes changed among mainland Chinese immigrants when the U.S. gave many of them permission to work and then a green card in response to the events at Tiananmen Square. 


\section{DATA AND METHODS}

We use a difference-in-differences (D-in-D) methodology to examine the effect of the postTiananmen immigration policies on mainland Chinese immigrants' labor market outcomes. The D-in-D methodology involves comparing the change in outcomes over time for one group with the change for another group (Angrist and Pischke, 2009). The method is quasi-experimental; a treatment group that is directly affected by a policy is compared with a control group that is not directly affected by the policy. Our treatment group is immigrants from mainland China, many of whom were eligible for the CSPA, and our control groups are immigrants from Hong Kong, Taiwan, or Korea, who were not eligible for the CSPA because the act applied only to mainland Chinese. Our "pre" period is the 1990 census, which was administered right before the executive order, and our "post" period is the 2000 census. We expect that employment and earnings increased among immigrants from mainland China relative to immigrants from the three other countries as a result of the post-Tiananmen policy changes.

The D-in-D methodology gives the average change among immigrants from mainland China relative to those from another country. The control group_-immigrants from Hong Kong, Taiwan, or Korea - is included to control for other factors that changed during the 1990s. For example, all of these groups of immigrants experienced employment and earnings changes as their duration of residence in the U.S. increased. Changes in labor market conditions, such as the high-tech boom in the late 1990s, also affected all of these groups.

The D-in-D method requires relatively few identifying assumptions. Mainly, it assumes that, absent the CSPA and related measures, immigrants from mainland China and the comparison countries would have experienced similar changes in labor market outcomes. In other words, we attribute to the CSPA and related measures any changes that occurred among 
mainland Chinese immigrants relative to the other Asian immigrants in our control groups. There is no way to test this assumption, but there is good reason to think it is valid. In particular, most Americans are unlikely to distinguish between immigrants from these countries but rather to consider them as interchangeably "Asian." These groups therefore are likely to face similar levels of racial discrimination, if any. We believe that the main difference, controlling for observable characteristics, is that PRC immigrants had easier access to legal work status and green cards than other Asian immigrants as a result of the executive order and the CSPA. ${ }^{6}$

We use 1990 and 2000 census data from the 5 percent public use samples from IPUMS to estimate the D-in-D model. The data are from the decennial census "long form," which included questions on individuals' age, sex, educational attainment, employment, and earnings. The labor market questions pertained to the previous calendar year. The questionnaire asked where individuals were born and when they entered the U.S. It asked about individuals' U.S. citizenship status but, unlike the INS data, did not include visa type or class of admission and we therefore are unable to isolate CSPA beneficiaries in the PRC sample. Each census captured individuals at a point in time. Although individuals cannot be linked across decennial censuses, a cohort of individuals with certain characteristics can be followed over time.

We follow the cohort of immigrants who reported arriving in the U.S. between 1980 and 1990. We use those cutoffs for several reasons. The 1986 IRCA allowed unauthorized

\footnotetext{
${ }^{5} \mathrm{We}$ also used Indian immigrants as a control group. The results comparable to Tables 3 and 4 here indicate statistically-significant relative employment and earnings gains among PRC male immigrants and statisticallysignificant relative employment gains among PRC female immigrants. The results comparable to Tables 5 and 6 here indicate statistically-significantly higher relative employment and earnings among PRC male immigrants who arrived in 1988-89.

${ }^{6} \mathrm{D}$-in-D studies are often able to test the validity of the identifying assumption - that the two groups would have experienced similar changes absent the policy shock-by comparing relative differences over another time period, typically before the policy shock occurs. We are not able to do so since almost none of the immigrants in our sample were present when the 1980 census was conducted, making it impossible for us to compare relative changes between 1980 and 1990. No other dataset has large enough samples combined with information on nativity to allow us to conduct this exercise.
} 
immigrants who could prove they had lived in the U.S. continuously since 1982 to legalize, so we expect that most Chinese who entered the U.S. before 1980 had already received green cards through IRCA by the time the CSPA was passed. INS data indicate that 93 percent of CSPA beneficiaries last arrived in the U.S. as nonimmigrants in 1980 or later. We cut off the cohort arrival period in 1990 because the CSPA required that beneficiaries be in the U.S. when the executive order was issued on April 11, 1990. That coincides with the month the census was administered, giving us a good picture of Chinese immigrants at the time.

We limit our sample to individuals aged 25 to 39 in 1990 (aged 35 to 49 in 2000) with at least a bachelor's degree. This age range allows us to focus on immigrants who are likely to already have graduated from college in 1990 and to have benefitted from the CSPA. This age range accounts for over two-thirds of CSPA green card beneficiaries. ${ }^{7}$

An important issue is what fraction of our mainland Chinese sample is comprised of CSPA beneficiaries. The Census Bureau estimates that the population of PRC immigrants aged 25-39 who entered the U.S. in 1980 or later totaled about 102,000 in 1990. The number of CSPA beneficiaries in that age range was almost 36,000 . The CSPA and related measures thus are likely to have directly affected at least one-third of PRC immigrants aged 25-39 in the 1990 census. In order to increase this fraction, we limit the sample to highly-educated immigrants. We define this as having at least a bachelor's degree. We do this because most CSPA beneficiaries were in the U.S. on student, exchange visitor, or skilled temporary worker visas and were college graduates. ${ }^{8}$ This likely drops most beneficiaries who were unauthorized immigrants from the sample but improves our ability to capture the effect of the CSPA and related measures. In the

\footnotetext{
${ }^{7}$ This calculation (and the later comparison to the census data) is based on subtracting the difference between the year CSPA beneficiaries received their green card and 1990 from the age reported in the INS LPR dataset.

${ }^{8}$ The vast majority of students were in graduate school (Fu, 1995), and presumably most exchange visitors held university degrees. Immigration policy requires most skilled temporary worker visa holders to have at least a bachelor's degree.
} 
1990 census, 43 percent of PRC immigrants aged 25-39 who arrived in 1980 or later report having at least a bachelor's degree, representing almost 44,000 people. We conservatively estimate that at least two-fifths of them received a green card as a result of the CSPA given the distribution of the CSPA green card recipients across nonimmigrant classes. ${ }^{9}$

Table 2 presents descriptive statistics for our census samples of college-graduate immigrants from mainland China, Hong Kong, Taiwan, and Korea by census year. ${ }^{10}$ The sample means indicate both similarities and differences across the countries. Immigrants are disproportionately male from all four countries. PRC immigrants are more likely to be enrolled in school in 1990. In terms of year of arrival, PRC immigrants are more concentrated in the late 1980s than the other groups. PRC immigrants self-report worse ability to speak English than immigrants from Hong Kong - which is not surprising since Hong Kong was a British territory until 1997— but better than immigrants from Taiwan or Korea.

Turning to labor market outcomes, there was a dramatic increase over time in the share of highly-educated PRC immigrants who worked the previous year, from 76 percent in the 1990 census to 94 percent in the 2000 census (an increase of 18 percentage points). There were large increases in employment among immigrants from Taiwan and Korea as well (16 and 20 percentage points, respectively). The corresponding increase among immigrants from Hong Kong was only 3 percentage points. Highly-educated PRC immigrants thus appear to have gained in employment relative to those from Hong Kong but not relative to those from Taiwan or Korea before controlling for observable characteristics.

\footnotetext{
${ }^{9}$ In the INS LPR data on CSPA beneficiaries, over 22,800 people estimated to have been aged 25-39 in 1990 last entered the U.S. on a student (F-1), exchange visitor (J-1), or skilled temporary worker (H-1) visa. Based on Orleans (1988), we assume that one-third of F-1 visa holders were undergraduates. Other CSPA-related LPR recipients may have had a bachelor's degree as well, particularly accompanying spouses and temporary visitors for business.

${ }^{10}$ The census includes separate codes for Korea, South Korea, and North Korea. We include those who report their birthplace as Korea or South Korea.
} 
The sample means point to similarities and differences in hourly earnings growth as well. Earnings are calculated as annual earnings in 1989 or 1999 divided by weeks worked and usual hours worked per week and are corrected for inflation using the Personal Consumption Expenditures deflator. Earnings are conditional on working. All groups experienced sizable earnings growth. In the 1990 census, PRC immigrants earned 16 percent less per hour, on average, than immigrants from Hong Kong, 21 percent less than immigrants from Taiwan, and 10 percent less than immigrants from Korea. By 2000, the gap had closed to 3 percent with respect to Hong Kong and 13 percent with respect to Taiwan, and PRC immigrants out earned those from Korea.

The comparison of means thus suggests that highly-educated immigrants from mainland China may have experienced earnings and employment growth as a result of getting legal permission to work and then green cards in large numbers. However, differences in the groups' demographic characteristics could account for some of the relative improvements. We therefore turn to multivariate regression analysis to examine the relative change in labor market outcomes controlling for demographic characteristics. We estimate the following basic model for both employment and log real hourly earnings:

$$
\begin{aligned}
& \mathrm{Y}_{\mathrm{it}}=\alpha+\beta_{1} \text { Year2000 }_{\mathrm{it}}+\beta_{2} \mathrm{PRC}_{\mathrm{it}}+\beta_{3} \mathrm{PRC}_{\mathrm{it}}{ }^{*}{\text { Year } 2000_{\mathrm{it}}}+\delta_{1} \text { Demographics }_{\mathrm{it}}+ \\
& \sigma \operatorname{State}_{i t}+\varepsilon_{\mathrm{it}}
\end{aligned}
$$

where $Y_{i t}$ is one of two measures of labor market outcomes for individual $i$, who is surveyed in year $t$. The first measure is a dummy variable indicating whether an individual worked in the previous year; we estimate logistic models and report estimated odds ratios for that outcome. The 
second measure is log real hourly earnings, conditional on employment; we estimate linear models and report estimated coefficients for that outcome.

The dummy variable Year $2000_{i t}$ is equal to one if an observation is from the 2000 census, our post-CSPA period. $P R C_{i t}$ is a dummy variable equal to one for a mainland Chinese immigrant (the treatment group). The coefficient on the interaction of the two dummy variables, $\beta_{3}$, measures the average change in labor market outcomes for the treatment group relative to the control group; this is the coefficient of interest and is presented first in the tables that report regression results.

We control for several measures of individuals' characteristics in the vector Demographics $_{i t}$. These include indicators for the self-reported degree of English fluency (not well, well, very well, and only English, with no English as the omitted category) and for the period of arrival (1982-1984, 1985-1986, and 1987-1990, with 1980-1981 as the omitted category). They also include a quartic in age, dummy variables for being married or divorced/widowed/separated (with never married as the omitted category), the total number of children present in the household and the number of children under age 5, a dummy variable for being enrolled in school, and a dummy variable for living in an urban area. We include state fixed effects, State $e_{i}$, to control for state-specific labor market determinants. Standard errors are Huber-White heteroscedasticity-corrected and clustered on the country of birth. Observations are weighted using the person weights provided by the census. We show results for men and women together and then separately by sex. 


\section{RESULTS}

The U.S. immigration policy response to Tiananmen appears to have had a large effect on employment of college-educated Chinese nationals. Table 3 reports the estimated odds ratios from the employment regressions. Relative to immigrants from Hong Kong, the odds ratios on the $P R C^{*}$ Year2000 interaction term are 3, 4.6, and 2 for all, men, and women, respectively, and are statistically significant at the 1 percent level (row 1 of Table 3 ). These estimates suggest that the odds that PRC immigrants worked increased by three times as much during the 1990s as among Hong Kong immigrants. Evaluated at sample means, the estimates for PRC*Year2000 are equivalent to a 6.4 percentage point rise in the relative probability of working for men and 9 percentage points for women. ${ }^{11}$ In addition, PRC immigrants went from being less likely to work than Hong Kong immigrants in 1990 to being more likely to do so in $2000 .^{12}$ The results thus suggest the relative employment odds of well-educated mainland Chinese immigrants rose after the CSPA and related measures and they became more likely to work than their counterparts from Hong Kong, with the relative gains larger for women than for men.

The results with Taiwan or Korea as the comparison group point to relative employment gains as well. Evaluated at sample means, the results for the $P R C^{*}$ Year2000 interaction term reported in panel B of Table 3 translate into gains of about 1.5 percentage points for PRC men relative to Taiwanese men, and 11 percentage points for PRC women. Relative to Koreans (panel C), PRC men had employment gains of about 2 percentage points, and PRC women 8 percentage points. Immigrants from mainland China are more likely to work than immigrants from Taiwan

\footnotetext{
${ }^{11}$ The estimate is larger for females than males even though the estimated coefficient is smaller because mean employment rates are lower among females.

${ }^{12}$ This can be seen by comparing the average employment odds among PRC immigrants relative to Hong Kong immigrants in 1990 (the odds ratio on the $P R C$ dummy variable, which is less than one) with the PRC*Year2000 interaction minus the estimated coefficient on the $P R C$ dummy variable, all evaluated at their sample means. Doing so results in a net PRC employment premium in 2000 of 6.1 percentage points for men and 5.6 percentage points for women.
} 
and Korea, as indicated by the estimated coefficients greater than one on the $P R C$ dummy variable. As a result, mainland Chinese men and women became even more likely to work than their Taiwanese and Korean counterparts in 2000, with the gains again larger for women than for men.

The control variables are also important determinants of employment but are not shown in the table. ${ }^{13}$ The years since migration variables generally are significantly related to employment, with the earlier cohorts more likely to be employed than latecomers. Other variables in the employment regressions indicate significantly higher odds of working among men and among immigrants who speak English well or very well. Being enrolled in school is significantly negatively related to the odds of working. Having children in the household is positively associated with employment among men and negatively associated with employment among women.

Turning to earnings, the results shown in Table 4 suggest that highly-educated PRC immigrants experienced relative wage gains after some got permission to work and then green cards in the aftermath of Tiananmen. In the regressions with Hong Kong as the control group, the estimated coefficient on $P R C^{*}$ Year2000 is positive and significant for the sexes separately and combined. The results suggest that male PRC immigrants' hourly wages rose by 26 percent relative to Hong Kong immigrants' wages as a result of the CSPA and related measures, and by 28 percent for women. ${ }^{14}$ Before the CSPA, PRC immigrants earned less than comparable Hong Kong immigrants, on average, as indicated by the negative coefficient on the $P R C$ dummy variable. In 2000, mainland Chinese immigrants with a bachelor's degree earned more than comparable Hong Kong immigrants; the sum of the interaction coefficient and the coefficient on

\footnotetext{
${ }_{13}^{13}$ Complete regression results are available on request.

${ }^{14}$ Because the dependent variable is the natural $\log$ of the real wage and the covariate of interest is a dummy variable, we transform the estimated coefficients as their antilog minus one.
} 
the $P R C$ dummy variable translates into a wage premium of about 8 percent for PRC men and 18 percent for PRC women in 2000.

Highly-educated PRC immigrants also experienced large wage gains relative to Korean immigrants. Mainland Chinese male immigrants experienced 30 percent faster wage growth than Korean male immigrants during the 1990s (panel C of Table 4). The relative gains are 20 percent among PRC women. PRC female immigrants also earned more than their Korean counterparts in 1990, as indicated by the positive coefficient on the $P R C$ dummy variable in the third column. This wage advantage thus increased further for PRC women in 2000.

Mainland Chinese immigrants experienced smaller wage gains relative to Taiwanese immigrants. The regressions yield a positive but not statistically significant coefficient on the $P R C^{*}$ Year2000 variable in the pooled sample and the male sample (panel B of Table 4). In the female sample, PRC immigrants experienced statistically-significant relative wage gains of about 11 percent. As a result, highly-educated female PRC immigrants went from earning 6 percent less than female Taiwanese immigrants in 1990 to earning about 5 percent more in 2000, controlling for observable characteristics.

The control variables are important determinants of wages. Earlier cohorts of immigrants earn more than latecomers, and more-fluent English speakers earn more than less-fluent English speakers. Being enrolled in school is not significantly related to wages, which are conditional on being employed. Highly-educated men earn about 20 percent more than comparable women. Being married or having children has a significant wage premium for men, but not women.

The above results pertain only to college graduates. In results not shown here, we typically obtained smaller positive, zero, or even negative results on the $P R C^{*}$ Year2000 variable when looking at less-educated groups of immigrants. Employment and earnings regressions for 
immigrants who had completed high school but not college or who had not completed high school did not yield a consistent pattern of gains among PRC immigrants relative to their Hong Kong, Taiwanese, or Korean counterparts in the wake of the CSPA and related measures. This is not surprising since a much smaller fraction of Chinese immigrants in those samples are likely to have received a green card under the CSPA than in our college-graduate sample.

The above earnings results are conditional on employment, yet there are clearly changes in employment among our treatment group, both absolutely and relative to the comparison group and particularly for women. We therefore also estimated selection-corrected earnings regressions that control for selection into employment. Identifying the selection-corrected regression model requires at least one variable that affects employment but does not directly affect earnings. We used the enrollment and children variables as the excluded variables. The selection-corrected results are similar to those shown in Table 4, suggesting little bias from not correcting for selection into employment.

Quite a few of the highly-skilled immigrants we examine here benefitted from the 1990s high-tech boom. There is no reason to think that PRC immigrants benefitted more than the comparison groups, but we tried including a dummy variable for working in the computer and data processing industry interacted with year dummy variables in the earnings regressions to control for this possibility. The results were similar to those shown in Table 4. In addition, the employment and earnings results were robust to interacting the state dummy variables with year dummy variables to capture differential growth across states. The results also were robust to using unweighted data and controlling for naturalized U.S. citizenship.

\section{Differences in 2000}


One concern about the above results is that there may have been differential return migration by Chinese immigrants and the control groups. The sample sizes indicate that there was virtually no return migration by mainland Chinese immigrants, a small amount of return migration to Hong Kong (less than 2 percent of the 1990 population), and considerable return migration to Taiwan and South Korea (about 18 percent and 23 percent, respectively). If there are cross-country differences in the selectivity of return migration, our comparison of changes over time would be biased. We do not know the relative direction of selection in return migration, or whether employment and earnings in 1990 were relatively high or low among migrants who returned to Taiwan and Hong Kong by 2000.

This concern motivates us to do a comparison using just data from 2000. We compare the difference in labor market outcomes among Chinese immigrants who arrived in the U.S. in time to be covered by the CSPA with Chinese immigrants who arrived later. The CSPA required that immigrants had been almost continuously present in the U.S. after the executive order was signed in April 1990. We therefore compare labor market outcomes in the 2000 census among Chinese immigrants who arrived in 1988-89 and were eligible for the CSPA with those who arrived in 1991-92 and were not eligible. ${ }^{15}$ Of course, immigrants who arrived in the U.S. earlier have had more time to assimilate and should have better labor market outcomes in any given year. This motivates our use of very narrow time windows that are close together. In addition, we compare the difference in outcomes in 2000 between the two groups of Chinese immigrants with the corresponding difference among immigrants from Hong Kong, Taiwan, or Korea, or

$$
\begin{gathered}
\mathrm{Y}_{\mathrm{i}}=\alpha+\beta_{1} \text { Entered in 1988-89 }+\beta_{2} \text { PRC }_{\mathrm{i}}+\beta_{3} \mathrm{PRC}_{\mathrm{i}}{ }^{*} \text { Entered in 1988-89 }+\delta_{1} \text { Demographics }_{\mathrm{i}}+ \\
\sigma_{\text {State }_{\mathrm{i}}}+\varepsilon_{\mathrm{i}}
\end{gathered}
$$

\footnotetext{
${ }^{15}$ This requires assuming that responses to the year of arrival question are accurate. Redstone and Massey (2004) discuss measurement error in this variable. Such measurement error should bias our results toward zero.
} 
Our focus is again on $\beta_{3}$, the D-in-D estimate.

The employment results, shown in Table 5, are positive. PRC immigrants who arrived in 1988-89 have higher employment rates in 2000 than those who arrived in 1991-92, compared to the same difference among immigrants from Hong Kong, Taiwan, or Korea. Interestingly, the results do not necessarily suggest that earlier immigrants were more likely to be employed, as some of the estimated coefficients on the Entered in 1988-89 dummy variable are greater than one and others are less than one. Most, but not all, of the estimates for the $P R C$ dummy variable are greater than one, indicating that both arrival cohorts from the PRC are more likely to work than those from the comparison country. But all of the estimates for the PRC *Entered in 1988-89 dummy variable are significantly greater than one.

The earnings results, shown in Table 6, also suggest positive effects of the CSPA. PRC immigrants who arrived early enough to be eligible for the CSPA have significantly higher earnings than those who arrived too late, compared to early and late arrivals from Hong Kong overall. The results by sex for Hong Kong are also positive but not statistically significant— the sample sizes are small because of the narrow time windows. Results are also positive overall and for men with Taiwan as the control group, and overall and for women with Korea as the control group. The results are mixed as to whether earlier immigrants have higher earnings than later immigrants and as to whether both cohorts of immigrants from the PRC earn more than those from the comparison country.

\section{DISCUSSION}


The results suggest that the policies giving permission to work legally and then green cards had a significant positive impact on the labor market outcomes of highly-educated immigrants from mainland China. Employment rates rose by 2 to 11 percentage points among college-graduate PRC immigrants relative to those from Hong Kong, Taiwan, or Korea. Relative employment gains were larger among PRC women than among men. Highly-educated PRC immigrants also experienced sizable wage growth, particularly relative to immigrants from Hong Kong and Korea. Relative employment and earnings gains were smaller or non-existent among PRC immigrants with less education. We also found evidence of higher earnings and employment among PRC immigrants who arrived in the U.S. in time to be eligible for the CSPA relative to those who arrived too late.

Our findings thus are consistent with previous research that finds large wage effects of granting permanent resident status to non-immigrants (Gass Kandilov, 2007; Mukhopadhyay and Oxborrow, 2010). Our results are also consistent with research suggesting that the effect of legalizing status is larger among more educated immigrants (Kaushal, 2006; Pan, 2010). Our results extend this finding from unauthorized migrants from Latin America — the primary beneficiaries of IRCA and NACARA - to Chinese migrants who were primarily in the U.S. on student and exchange visitor visas.

The difference-in-differences methodology rests on a key assumption that merits revisiting. This assumption is that the post-CSPA outcomes of the treatment and control groups differ only because PRC immigrants received the "treatment"- they could bypass the normal channels to get a green card. But other changes may have impacted the treatment and control groups differently and, as a result, affected their outcomes in the post-treatment period. This motivates our use of three different countries as control groups. Nonetheless, differential changes 
may have occurred between PRC immigrants and immigrants from the other three countries. The fact that the results differ somewhat in magnitude across comparison groups suggests that this is the case. The most likely source of such changes is differential selection in return migration or initial migration.

As discussed above, differential selection in return migration would bias the first set of D-in-D results. There is no way to know which direction is the case since the U.S. does not collect data on return migrants. The fact that the first and second sets of D-in-D results are similar suggests that differential selection in return migration does not bias the results.

Another potential source of bias is systematic unobservable differences between immigrants from PRC and the comparison countries. Chinese universities were closed from 1966 to 1970-71 as part of the Cultural Revolution. When they reopened, few students were allowed to attend them and the quality of education was low. In 1977, Chinese universities resumed competitive entrance exams. Entrance was extraordinarily competitive for the next few years (Meng and Gregory, 2002). In 1978, China resumed allowing some of its citizens to study abroad, and the Chinese government played an active role in determining who would be allowed to do so. These dramatic shifts in Chinese education policy may have resulted in Chinese nationals who studied in the U.S. during the 1980s being particularly positively selected both relative to the Chinese population and relative to their counterparts from other Asian nations. However, the characteristics on which China selected which students were allowed to study abroad may not necessarily be those that were particularly highly valued in the U.S. labor market. As with selective return migration, we are unable to assess the magnitude or even direction of bias selective migration would impart to our estimates. 
Not all PRC immigrants we treat here as affected by the U.S. immigration policy response to Tiananmen were directly affected by those measures. The presence of those unaffected observations in the "treatment" group biases the results toward zero. At the same time, some of the immigrants in the three control groups also received green cards through regular channels, which also biases the results toward zero. Nonetheless, the policy reaction to the events in Tiananmen clearly allowed eligible Chinese immigrants to get permission to work legally and then obtain a green card more quickly and more easily than via regular channels and therefore is likely to have affected their labor market outcomes, consistent with our results.

Other immigration policy changes may interfere with our identifying assumptions. For example, fewer employment-based green cards may have been available to PRC immigrants in the post-CSPA years because of the mandated offset of the CSPA green cards. This could have reduced competition from other employment-based immigrants. At the same time, however, the Immigration Act of 1990 significantly expanded the number of employment-based green cards. These changes in the number of green cards available may have offset each other for immigrants from mainland China. ${ }^{16}$

\section{CONCLUSION}

The 1989 student protests in Tiananmen Square and the government crackdown that followed are sensitive topics to this day. PRC immigrants who came then or in the years following are still fearful to speak of their roles in the uprising or even where their sympathies might lie. PRC

\footnotetext{
${ }^{16}$ As Figure 1 shows, there is little change in the trend in the number of green cards issued to mainland Chinese if CSPA beneficiaries are removed from the data. The Visa Bulletins issued by the State Department in 1995 indicate that the $3^{\text {rd }}$ preference category for employment-based green cards had a priority date of July 1, 1993, in January 1995 but that the queue had cleared by the end of 1995 . This is consistent with the possibility that some employment-based immigrants had to wait for green cards as a result of the CSPA offset, but the wait also could have been the result of an increase in LPR applications for reasons other than the CSPA. As of January 1995, immigrants from mainland China trying to enter in the $2^{\text {nd }}, 3^{\text {rd }}$, or $4^{\text {th }}$ family-based preference categories faced priority dates ranging from 1985 to 1992, suggesting that those categories were already backed up before the CSPA.
} 
natives refer to "blood cards," the pejorative term for the green cards awarded to those who, by virtue of their presence in the U.S. at the time, benefited from the Chinese Student Protection Act while some of their countrymen died in Tiananmen Square.

This paper asks how PRC immigrants' labor market prospects might have been affected by the U.S. government's actions in the wake of Tiananmen Square. We find that collegegraduate mainland China immigrants who arrived in the 1980s outperformed control groups of immigrants from Hong Kong, Taiwan, and Korea in the decade that followed. In the wake of the CSPA and related measures, highly-educated PRC immigrants experienced larger increases in employment and wages than did immigrants from the three other countries. Female PRC immigrants benefited more than men in terms of employment. We find much smaller relative changes among less educated immigrants. These findings are consistent with the literature on the wage effects of green cards and, more broadly, legalization programs. The results suggest that highly-skilled immigrants on temporary, primarily student, visas benefit greatly from quickly transitioning to permanent resident status. 


\section{REFERENCES}

Amuedo-Dorantes, Catalina, Cynthia Bansak, and Steven Raphael (2007). "Gender Differences in the Labor Market: Impact of IRCA's Amnesty Provisions." American Economic Review Papers \& Proceedings 97 (May): 412-416.

Angrist, Joshua D., and Jörn-Steffen Pischke (2009). Mostly Harmless Econometrics Princeton, NNJ: Princeton University Press.

Brooks, Jack (1992). Chinese Student Protection Act of 1992. Report to Accompany S. 1216 of the Committee on the Judiciary, House of Representatives, 102d Congress, 2d Session.

Washington, DC: U.S. Congress, House Committee on the Judiciary.

Chi, Miao, and Scott Drewianka (2010). "How Much Is a Green Card Worth? Evidence from Mexican and Puerto Rican Men Who Marry Women Born in the U.S.” Mimeo, Department of Economics, University of Wisconsin-Madison.

$\mathrm{Fu}$, Xuanning (1995). "Impact of the 1993 Chinese Student Protections Act on American and Chinese Societies." Journal of Northeast Asian Studies 14 (June): 3-22.

Gass Kandilov, Amy M. (2007). "The Value of a Green Card: Immigrant Wage Increases Following Adjustment to U.S. Permanent Residence." Manuscript, University of Michigan.

Kaushal, Neeraj (2006). "Amnesty Programs and the Labor Market Outcomes of Undocumented Immigrants.” Journal of Human Resources 41 (Summer): 631-647.

Kossoudji, Sherrie A., and Deborah A. Cobb-Clark (2002). "Coming out of the Shadows: Learning about Legal Status and Wages from the Legalized Population." Journal of Labor Economics 20 (July): 598-628.

Lan, Xiaohuan (2009). "Permanent Visas and Temporary Jobs: Evidence from Postdoctoral Participation of Foreign PhDs in the U.S.” Mimeo, Department of Economics, University of Virginia.

Mann, Jim (1990). "China's Lost Generation: After Tian An Men, the Best and Brightest Say They Can't Go Home Again.” Los Angeles Times Magazine, March 25.

Meng, Xin, and R. G. Gregory (2002). "The Impact of Interrupted Education on Subsequent Educational Attainment: A Cost of the Chinese Cultural Revolution." Economic Development and Cultural Change 50 (July): 935-959.

Mukhopadhyay, Sankar, and David Oxborrow (2010). "The Value of an Employment-Based Green Card." Forthcoming, Demography.

Myers, Willard H., III (1994). Testimony on April 21, 1994, before the Subcommittee on Terrorism, Narcotics and International Operations of the Committee on Foreign Relations, U.S. Senate, 103rd Congress, $2^{\text {nd }}$ session. (available online at 
http://www.archive.org/stream/recentdevelopments1994unit/recentdevelopments1994unit_djvu.t $x t)$.

Orleans, Leo A. (1988). Chinese Students in America: Policies, Issues, and Numbers. Washington, DC: National Academy Press.

Pan, Ying (2010). "The Impact of Legal Status on Immigrants' Earnings and Human Capital: Evidence from the IRCA 1986.” Working Paper 2010-02, Department of Economics, Louisiana State University.

Poston, Dudley L., Jr., and Hua Luo (2006). "Chinese Student and Labor Migration to the United States: Trends and Policies since the 1980s." Paper presented at Conference on Global Competition for International Students, Georgetown University, March.

Redstone, Ilana, and Douglas S. Massey (2004). "Coming to Stay: An Analysis of the U.S. Census Question on Immigrants' Year of Arrival.” Demography 41 (November): 721-738.

Rivera-Batiz, Francisco L. (1999). "Undocumented Workers in the Labor Market: An Analysis of the Earnings of Legal and Illegal Mexican Immigrants in the United States." Journal of Population Economics 12 (February): 91-116.

Rytina, Nancy (2002). "IRCA Legalization Effects: Lawful Permanent Residence and Naturalization through 2001." Paper presented at Conference on The Effects of Immigrant Legalization Programs on the United States, National Institutes of Health, October.

U.S. Bureau of the Census (1993). The Foreign-Born Population in the United States. Report CP-3-1. Washington, DC: U.S. Department of Commerce (available online at http://www.census.gov/prod/cen1990/cp3/cp-3-1.pdf).

U.S. Immigration and Naturalization Service, Office of Policy and Planning (2003). "Estimates of the Unauthorized Immigrant Population Residing in the United States: 1990 to 2000." Washington, DC: U.S. Immigration and Naturalization Service (available online at http://www.dhs.gov/xlibrary/assets/statistics/publications/Ill_Report_1211.pdf). 
Figure 1

Legal permanent resident visas issued to Chinese nationals

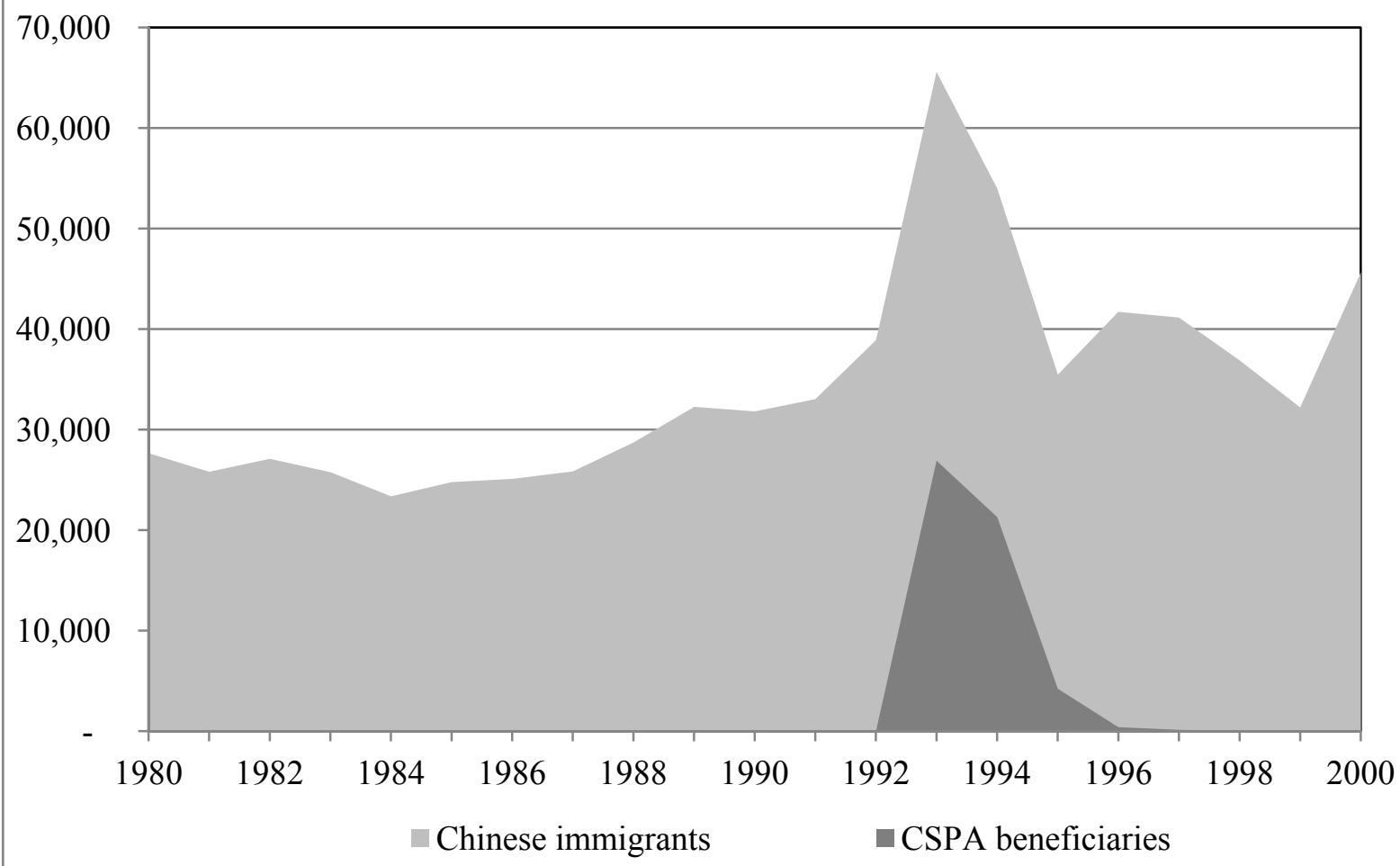

Note: Data are by fiscal year. Source: Yearbook of Immigration Statistics, various years. 
Table 1

Characteristics of CSPA and other East Asian recipients of LPR status in INS data

\begin{tabular}{lccccc}
\hline & CSPA & PRC & Hong Kong & Taiwan & Korea \\
& $1993-95$ & $1982-90$ & $1982-90$ & $1982-90$ & $1982-90$ \\
\hline Age & 34.7 & 39.1 & 24.2 & 28.7 & 27.2 \\
Male & 59.4 & 46.5 & 49.5 & 46.0 & 42.5 \\
Occupation & & & & & \\
$\quad$ Any occupation & 31.9 & 55.4 & 46.7 & 43.3 & 27.6 \\
Student or under 16 & 21.4 & 15.4 & 38.0 & 28.4 & 33.1 \\
$\quad$ Homemaker & 1.5 & 11.1 & 9.1 & 12.9 & 12.5 \\
$\quad$ Unemployed or retired & 5.3 & 16.1 & 4.7 & 12.0 & 24.2 \\
$\quad$ Not reported & 39.8 & 2.0 & 1.6 & 3.3 & 2.6 \\
Adjusted from nonimmigrant status & 100.0 & 17.2 & 21.2 & 35.5 & 11.8 \\
Nonimmigrant class at last entry (if adjusted status) & & & & \\
$\quad$ Student (F-1) & 40.2 & 23.5 & 35.4 & 34.5 & 17.3 \\
Spouse or child of student (F-2) & 10.8 & 3.0 & 0.8 & 9.4 & 6.3 \\
Skilled temporary worker (H-1) & 8.7 & 3.6 & 9.4 & 8.0 & 2.4 \\
Spouse or child of temporary worker (H-4) & 3.5 & 1.6 & 2.4 & 4.7 & 2.4 \\
Exchange visitor (J-1) & 8.0 & 3.5 & 0.8 & 0.7 & 0.4 \\
$\quad$ Spouse or child of exchange visitor (J-2) & 4.1 & 1.4 & 0.2 & 0.4 & 0.3 \\
Temporary visitor for pleasure (B-2) & 7.7 & 38.5 & 28.9 & 25.4 & 38.2 \\
Parolee & 7.1 & 1.4 & 0.8 & 0.3 & 0.7 \\
Other & 9.9 & 23.5 & 21.3 & 16.6 & 32.0 \\
Number & 52,722 & 243,604 & 62.942 & 113,925 & 290,350 \\
\hline
\end{tabular}

Source: Authors' calculations from INS legal immigrant public use files. The years indicated are fiscal years. "PRC" is mainland China (the People's Republic of China). 
Table 2

Descriptive statistics for census samples, both sexes

\begin{tabular}{|c|c|c|c|c|c|c|c|c|}
\hline \multirow[b]{2}{*}{ Variable } & \multicolumn{4}{|c|}{1990 census } & \multicolumn{4}{|c|}{2000 census } \\
\hline & PRC & Hong Kong & Taiwan & Korea & PRC & Hong Kong & Taiwan & Korea \\
\hline \multirow[t]{2}{*}{ Worked last year } & 0.76 & 0.88 & 0.70 & 0.62 & 0.94 & 0.91 & 0.86 & 0.82 \\
\hline & $(0.43)$ & $(0.33)$ & $(0.46)$ & $(0.49)$ & $(0.24)$ & $(0.28)$ & $(0.35)$ & $(0.39)$ \\
\hline \multirow{2}{*}{ Real hourly earnings } & 16.05 & 18.43 & 20.23 & 17.87 & 30.37 & 31.20 & 34.92 & 26.43 \\
\hline & $(23.53)$ & $(14.76)$ & $(54.10)$ & $(31.69)$ & $(41.81)$ & $(44.17)$ & $(74.01)$ & $(39.06)$ \\
\hline Year of arrival 1980-1981 & 0.10 & 0.28 & 0.18 & 0.14 & 0.08 & 0.29 & 0.23 & 0.22 \\
\hline Year of arrival 1982-1984 & 0.14 & 0.33 & 0.28 & 0.24 & 0.14 & 0.26 & 0.32 & 0.30 \\
\hline Year of arrival 1985-1986 & 0.25 & 0.12 & 0.19 & 0.23 & 0.24 & 0.19 & 0.21 & 0.19 \\
\hline Year of arrival 1987-1990 & 0.51 & 0.27 & 0.36 & 0.39 & 0.54 & 0.27 & 0.24 & 0.29 \\
\hline Age & 31.18 & 29.90 & 31.50 & 31.44 & 40.58 & 40.07 & 41.73 & 41.71 \\
\hline Male & 0.58 & 0.57 & 0.53 & 0.53 & 0.56 & 0.54 & 0.48 & 0.51 \\
\hline Married & 0.73 & 0.48 & 0.71 & 0.83 & 0.89 & 0.80 & 0.88 & 0.88 \\
\hline Divorced, widowed, separated & 0.03 & 0.03 & 0.02 & 0.03 & 0.06 & 0.05 & 0.06 & 0.07 \\
\hline Number of children & 0.35 & 0.32 & 0.62 & 0.94 & 1.24 & 1.13 & 1.45 & 1.58 \\
\hline Number of children under age 5 & 0.21 & 0.19 & 0.39 & 0.56 & 0.38 & 0.34 & 0.29 & 0.20 \\
\hline Enrolled in school & 0.56 & 0.34 & 0.41 & 0.34 & 0.09 & 0.11 & 0.06 & 0.11 \\
\hline Urban & 0.98 & 0.98 & 0.99 & 0.99 & 0.98 & 0.98 & 0.99 & 0.99 \\
\hline Speaks English not at all & 0.01 & 0.00 & 0.00 & 0.01 & 0.01 & 0.00 & 0.00 & 0.01 \\
\hline Speaks English not well & 0.11 & 0.05 & 0.09 & 0.25 & 0.04 & 0.04 & 0.05 & 0.20 \\
\hline Speaks English well & 0.44 & 0.39 & 0.55 & 0.47 & 0.33 & 0.34 & 0.48 & 0.48 \\
\hline Speaks English very well & 0.42 & 0.51 & 0.33 & 0.24 & 0.60 & 0.57 & 0.43 & 0.28 \\
\hline Speaks only English & 0.02 & 0.05 & 0.02 & 0.03 & 0.02 & 0.05 & 0.03 & 0.03 \\
\hline $\mathrm{N}$ & 1,864 & 488 & 2,663 & 2,292 & 2,256 & 486 & 2,259 & 1,854 \\
\hline
\end{tabular}

Source: Authors' calculations from 1990 and 2000 census data. Standard deviations are in parentheses.

Note: Shown are descriptive statistics for immigrants aged 25 to 39 in 1990 and aged 35 to 49 in 2000 who arrived in the U.S. between 1980 and 1990 and have at least a bachelor's degree. Earnings are deflated using the PCE deflator (2005=100) and conditional on working last year. Sample sizes are unweighted; all other data are based on person weights. 
Table 3

D-in-D regression results for employment, 1990 versus 2000

\begin{tabular}{lccc}
\hline & $\begin{array}{c}\text { All } \\
(1)\end{array}$ & $\begin{array}{c}\text { Men } \\
(2)\end{array}$ & $\begin{array}{c}\text { Women } \\
(3)\end{array}$ \\
\hline A. Relative to Hong Kong & & & \\
PRC Year 2000 & $3.007^{* *}$ & $4.597^{* *}$ & $1.995^{* *}$ \\
PRC & $(0.107)$ & $(0.005)$ & $(0.128)$ \\
& $0.557^{* *}$ & $0.348^{* *}$ & $0.809^{*}$ \\
Year 2000 & $(0.004)$ & $(0.060)$ & $(0.076)$ \\
& 1.095 & $1.078^{* *}$ & 1.300 \\
& $(0.341)$ & $(0.020)$ & $(0.535)$ \\
B. Relative to Taiwan & & & \\
PRC*Year 2000 & & & \\
& $2.035^{* *}$ & $1.321^{* *}$ & $1.923^{* *}$ \\
PRC & $(0.169)$ & $(0.065)$ & $(0.131)$ \\
& $1.602^{* *}$ & $1.586^{* *}$ & $1.792^{* *}$ \\
Year 2000 & $(0.034)$ & $(0.045)$ & $(0.014)$ \\
& $1.776^{* *}$ & $4.973^{* *}$ & $1.463^{*}$ \\
C. Relative to Korea & $(0.234)$ & $(0.753)$ & $(0.244)$ \\
PRC*Year 2000 & & & \\
& & & \\
PRC & $1.629 * *$ & $1.398^{* *}$ & $1.507^{* *}$ \\
& $(0.112)$ & $(0.138)$ & $(0.159)$ \\
Year 2000 & $2.259^{* *}$ & $2.071^{* *}$ & $2.790^{* *}$ \\
& $(0.145)$ & $(0.252)$ & $(0.013)$ \\
& 1.316 & $2.389^{*}$ & 1.247 \\
& $(0.347)$ & $(0.997)$ & $(0.279)$ \\
& & &
\end{tabular}

Significance levels are denoted ${ }^{\dagger} \mathrm{p}<0.1 ; * \mathrm{p}<0.05 ; * * \mathrm{p}<0.01$.

Source: Authors' calculations from 1990 and 2000 census data.

Note: Shown are estimated odds ratios from logistic regressions, with standard errors shown in parentheses. The sample includes immigrants aged 25 to 39 in 1990 and aged 35 to 49 in 2000 who arrived in the U.S. between 1980 and 1990 and have at least a bachelor's degree. The regressions also include controls for the demographic characteristics listed in Table 2 (see text for details) and state of residence. Standard errors are clustered on country. 
Table 4

D-in-D regression results for log of real hourly earnings, conditional on employment, 1990 versus 2000

\begin{tabular}{lccc}
\hline & $\begin{array}{c}\text { All } \\
(1)\end{array}$ & $\begin{array}{c}\text { Men } \\
(2)\end{array}$ & $\begin{array}{c}\text { Women } \\
(3)\end{array}$ \\
\hline A. Relative to Hong Kong & & & \\
PRC*Year 2000 & $0.242^{*}$ & $0.232^{*}$ & $0.248^{\dagger}$ \\
PRC & $(0.011)$ & $(0.007)$ & $(0.028)$ \\
& -0.143 & $-0.169^{\dagger}$ & -0.107 \\
Year 2000 & $(0.026)$ & $(0.026)$ & $(0.028)$ \\
& $0.301^{*}$ & $0.356^{* *}$ & $0.247^{\dagger}$ \\
B. Relative to Taiwan & $(0.013)$ & $(0.001)$ & $(0.038)$ \\
PRC*Year 2000 & & & \\
PRC & & & \\
& 0.085 & 0.054 & $0.104^{*}$ \\
Year 2000 & $(0.022)$ & $(0.024)$ & $(0.007)$ \\
& -0.097 & -0.112 & $-0.057^{*}$ \\
C. Relative to Korea & $(0.019)$ & $(0.032)$ & $(0.004)$ \\
PRC*Year 2000 & $0.418^{*}$ & $0.478^{*}$ & $0.374^{*}$ \\
PRC & $(0.016)$ & $(0.038)$ & $(0.010)$ \\
& & & \\
Year 2000 & & & $0.167^{\dagger}$ \\
& $0.223^{*}$ & $0.261^{* *}$ & $0.019)$ \\
& $(0.007)$ & $(0.002)$ & $(0.019)$ \\
& 0.067 & 0.066 & $0.091^{*}$ \\
& $(0.013)$ & $(0.032)$ & $(0.005)$ \\
& 0.266 & 0.255 & 0.310 \\
& $(0.066)$ & $(0.068)$ & $(0.053)$ \\
& & &
\end{tabular}

Significance levels are denoted ${ }^{\dagger} \mathrm{p}<0.1 ; * \mathrm{p}<0.05 ; * * \mathrm{p}<0.01$.

Source: Authors' calculations from 1990 and 2000 census data.

Note: Shown are estimated coefficients from linear regressions, with standard errors shown in parentheses. The sample includes immigrants from PRC and Hong Kong aged 25 to 39 in 1990 and aged 35 to 49 in 2000 who arrived in the U.S. between 1980 and 1990 and have at least a bachelor's degree. The regressions also include controls for the demographic characteristics listed in Table 2 (see text for details) and state of residence. Standard errors are clustered on country. 
Table 5

D-in-D regression results for employment in 2000 among Chinese immigrants by period of entry, 1988-89 versus 1991-92

\begin{tabular}{lccc}
\hline & All & Men & Women \\
& $(1)$ & $(2)$ & $(3)$ \\
\hline A. Relative to Hong Kong & & & \\
\hline PRC*Entered in 1988-89 & $1.479^{* *}$ & $2.904^{* *}$ & $1.272^{* *}$ \\
& $(0.028)$ & $(0.402)$ & $(0.004)$ \\
PRC & $1.202^{* *}$ & $1.649^{*}$ & $1.209^{*}$ \\
& $(0.053)$ & $(0.384)$ & $(0.028)$ \\
Entered in 1988-89 & $1.127^{* *}$ & $1.554^{* *}$ & $1.204^{* *}$ \\
& $(0.028)$ & $(0.224)$ & $(0.082)$ \\
B. Relative to Taiwan & & & \\
PRC*Entered in 1988-89 & $1.813^{* *}$ & $1.783^{* *}$ & $1.986^{* *}$ \\
& $(0.069)$ & $(0.117)$ & $(0.321)$ \\
PRC & $2.087^{* *}$ & $0.665^{* *}$ & $2.377^{* *}$ \\
& $(0.058)$ & $(0.001)$ & $(0.183)$ \\
Entered in 1988-89 & 0.925 & $2.498^{* *}$ & $0.725^{*}$ \\
& $(0.082)$ & $(0.540)$ & $(0.111)$ \\
C. Relative to Korea & & & \\
PRC*Entered in 1988-89 & & & $1.869^{* *}$ \\
& $2.063^{* *}$ & $2.975^{* *}$ & $(0.246)$ \\
PRC & $(0.094)$ & $(0.667)$ & $3.062^{* *}$ \\
& $2.439^{* *}$ & 1.235 & $(0.968)$ \\
Entered in 1988-89 & $(0.716)$ & $(0.417)$ & $0.733^{* *}$ \\
& $0.780^{* *}$ & 1.257 & $(0.065)$ \\
\hline
\end{tabular}

Significance levels are denoted ${ }^{\dagger} \mathrm{p}<0.1 ; * \mathrm{p}<0.05 ; * * \mathrm{p}<0.01$.

Source: Authors' calculations from 2000 census data.

Note: Shown are estimated odds ratios from logistic regressions, with standard errors shown in parentheses. The sample includes immigrants aged 35 to 49 who have at least a bachelor's degree. The regressions also include controls for the demographic characteristics listed in Table 2 (see text for details) and state of residence. Standard errors are clustered on country. 
Table 6

$D$-in-D regression results for log of real hourly earnings, conditional on employment, in 2000 among Chinese immigrants by period of entry, 1988-89 versus 1991-92

\begin{tabular}{lccc}
\hline & $\begin{array}{c}\text { All } \\
(1)\end{array}$ & $\begin{array}{c}\text { Men } \\
(2)\end{array}$ & $\begin{array}{c}\text { Women } \\
(3)\end{array}$ \\
\hline A. Relative to Hong Kong & & & \\
\hline PRC*Entered in 1988-89 & $0.248^{* *}$ & 0.227 & 0.286 \\
PRC & $(0.002)$ & $(0.037)$ & $(0.058)$ \\
& -0.153 & $-0.127^{\dagger}$ & -0.224 \\
Entered in 1988-89 & $(0.025)$ & $(0.014)$ & $(0.074)$ \\
& $-0.125^{* *}$ & -0.115 & -0.158 \\
B. Relative to Taiwan & $(0.001)$ & $(0.033)$ & $(0.047)$ \\
PRC*Entered in 1988-89 & & & \\
& & & -0.008 \\
PRC & $0.062^{\dagger}$ & $0.118^{*}$ & $(0.033)$ \\
& $(0.008)$ & $(0.005)$ & 0.045 \\
Entered in 1988-89 & $-0.065^{\dagger}$ & -0.167 & $(0.032)$ \\
& $(0.009)$ & $(0.034)$ & 0.132 \\
C. Relative to Korea & $0.066^{*}$ & 0.001 & $(0.031)$ \\
PRC*Entered in 1988-89 & $(0.003)$ & $(0.111)$ & \\
& & & $0.310^{*}$ \\
PRC & $0.084^{\dagger}$ & -0.039 & $(0.016)$ \\
Entered in 1988-89 & $(0.009)$ & $(0.012)$ & $-0.080^{\dagger}$ \\
& $0.163^{* *}$ & $0.324^{* *}$ & $(0.008)$ \\
& $(0.001)$ & $(0.001)$ & $-0.188^{\dagger}$ \\
& 0.036 & $0.149^{\dagger}$ & $(0.015)$ \\
\hline
\end{tabular}

Significance levels are denoted ${ }^{\dagger} \mathrm{p}<0.1 ; * \mathrm{p}<0.05 ; * * \mathrm{p}<0.01$.

Source: Authors' calculations from 2000 census data.

Note: Shown are estimated coefficients from linear regressions, with standard errors shown in parentheses. The sample includes immigrants 35 to 49 who have at least a bachelor's degree. The regressions also include controls for the demographic characteristics listed in Table 2 (see text for details) and state of residence. Standard errors are clustered on country. 